\title{
Haiti: The South African perspective
}

\author{
Daniël J van Hoving, Wayne P Smith, Efraim B Kramer, Shaheem de Vries, Fathima Docrat, Lee A Wallis
}

Background and problem statement. The South African response to the Haitian earthquake consisted of two independent nongovernment organisations (NGOs) working separately with minimal contact. Both teams experienced problems during the deployment, mainly owing to not following the International Search and Rescue Advisory Group (INSARAG) guidelines. Critical areas identified. To improve future South African disaster responses, three functional deployment categories were identified: urban search and rescue, triage and initial stabilisation, and definitive care. To best achieve this, four critical components need to be taken into account: rapid deployment, intelligence from the site, government facilitation, and working under the auspices of recognised organisations such as the United Nations and the World Health Organization.
Conclusion. The proposed way forward for South African medical teams responding to disasters is to be unified under a leading academic body, to have an up-to-date volunteer database, and for volunteers to be current with the international search and rescue course currently being developed by the Medical Working Group of INSARAG. An additional consideration is that South African rescue and relief personnel have a primary responsibility to the citizens of South Africa, then the Southern African Development Community region, then the rest of the African continent and finally further afield. The commitment of government, private and military health services as well as NGOs is paramount for a unified response.

S Afr Med J 2010; 100: 513-515
The Haitian earthquake resulted in an outpouring of international rescue and relief. ${ }^{1}$ South Africa's response consisted of the deployment of two non-government organisations (NGOs) working separately with minimal contact. This article describes the fragmented response and some of the problems experienced while in Haiti. More importantly, it argues the need to establish a unified South African disaster response system.

\section{Fragmented SA response}

The assistance from South Africa consisted of two independent NGOs: Rescue South Africa (RSA) and the Gift of the Givers Foundation. RSA dispatched a medium urban search and rescue (USAR) team comprising 2 civil engineers, 2 emergency doctors, $3 \mathrm{~K} 9$ rescue dogs with handlers, 4 media personnel and 31 search and rescue personnel (the latter from various metropolitan emergency services and provincial ambulance training colleges). The team arrived via a chartered flight with 8.5 tons of equipment 5 days after the earthquake, and then set up camp at the Port au Prince International Airport together with other International Search and Rescue Advisory Group (INSARAG) international teams. They were given tasks every

Division of Emergency Medicine, Stellenbosch University, Tygerberg, W Cape, and University of Cape Town

Daniël J van Hoving, MMed

Wayne P Smith, ACEM, EMDM

Shaheem de Vries, MPhil

Lee A Wallis, MD, FCEM

Division of Emergency Medicine, University of the Witwatersrand, Johannesburg Efraim B Kramer, FCEM

Neuroscience and Pain Division, Pfizer, Johannesburg

Fathima Docrat, MB ChB day by the INSARAG On-Site Operations Co-ordination Centre (OSOCC). The duration of the mission, which was specifically urban search and rescue, was 10 days.

The Gift of the Givers Foundation sent 4 teams, totalling 53 individuals. The teams varied considerably, consisting of urban search and rescue personnel, health care professionals and a media contingent. The health care component included professional nurses, medical practitioners, specialist emergency physicians and an assortment of other specialists or registrars. The teams were deployed in a staged response, arriving 2 days apart with a 2-day overlap before departure. The first team was a dedicated USAR team, the second team had rescue and medical personnel, and the third and fourth teams were mainly medical personnel. The foundation also shipped donated aid supplies to Haiti. ${ }^{2}$

\section{Areas of concern}

While the organisations and individuals concerned worked with the very best interests of the affected population at heart, the response overall was far from perfect. The following problem areas inter alia were identified among the two NGOs:

- There was no medical examination of, or notification of chronic medical conditions among, team members before departure; this resulted in several personnel being medically unfit to work in the demanding conditions in Haiti. Little attention was given to ensuring that members were up to date with vaccinations and taking malaria prophylaxis or personal medications. The health of each team member is critical to ensure a successful response.

- No team members were specifically dedicated to fulfil the key role of logistic manager, medical manager or operational manager. As is often the case, no one takes responsibility if everyone is responsible for an action; this was seen in the Haitian response, and on many occasions inefficiencies occurred as people did things their own way. 
- The use of commercial flights resulted in equipment being left in South Africa, forcing teams to work without essential tools, therefore limiting their spectrum of work. The transport of medical oxygen is also not permitted on commercial flights.

- The lack of a formalised pre-departure briefing left everyone wondering what to expect, which unnecessarily elevated tensions in each team member. An emergency evacuation plan should also have been discussed before departure.

- Formal trauma debrief sessions were not held to aid the integration of team members back into society. The volunteer teams, being exposed to large-scale destruction and death, are at high risk of developing post-traumatic stress disorders. ${ }^{3}$

- International guidelines for daily calorie requirements were not adhered to. Lack of energy not only dampens teams' spirits but, in addition, externally provided food sources in disaster situations are usually limited and are potentially unsafe, in addition to putting unnecessary demands on an already overstretched local supply chain.

- Appropriate clothing for the local conditions was not adequately considered, leaving team members at risk of dehydration and other heat-related illnesses.

- In a disaster situation, a deploying doctor is often required to function as safety officer, addressing issues such as the establishment and daily inspection of latrines, cleanliness of the camp, food storage and so on. Appropriate briefing and preparation is required for such tasks, which fall outside the remit of most doctors' daily responsibilities.

The INSARAG guidelines are well known in disaster medicine circles and should be adhered too. These guidelines are intended as a reference for countries aiming to establish international USAR capabilities. It is a detailed recommendation from different contributing authors who have gained experience in developing domestic USAR capability and responding to both major domestic and international USAR incidents. ${ }^{4}$

\section{Disaster preparedness}

The South African response to the Haitian earthquake was not ideal. In plotting a way forward for South African medical teams to be prepared to respond to disasters, we must first consider what is expected of such teams once they are deployed. Three functional categories can be identified, based on tasks and assistance required: (i) search and rescue; (ii) triage and initial stabilisation; and (iii) definitive medical care.

\section{Search and rescue}

Major natural and man-made disasters result in enormous damage to buildings and other structures, which invariably results in the trapping or burial of people. ${ }^{5}$ Initial rescue is usually done by the local population. However, a more technical response may be required. International USAR teams must be able to deploy quickly to assist in such incidents. The survivability of trapped survivors decreases greatly with time. ${ }^{5}$ Deployment time is determined not only by having an equipped and able team available, but also by when a request for international assistance from the affected country is made. ${ }^{6}$ The sooner the request is made, the sooner a prepared team can be deployed.

The required resources to deploy in the acute phase of search and rescue (SAR) are determined by the nature of the damage as well as the availability of suitable skills and equipment in the affected country. Therefore, intelligence from 'ground zero' is critical. This is now easier after the introduction of a virtual OSOCC. ${ }^{7}$ The role of the South African government, and especially of the Departments of Foreign Affairs and International Relations and Co-operation, as well as the National Disaster Management Centre, is critical in ensuring a smooth and timely deployment. Working under the auspices of global organisations such as INSARAG or the World Health Organization (WHO) is the last critical component for a medical response. ${ }^{6}$

The first phase of response encompasses SAR, and requires: (i) rapid deployment; (ii) intelligence from the site; (iii) government facilitation; and (iv) falling under the auspices of recognised organisations such as the UN and WHO.

\section{Triage and stabilisation}

The second of the functional categories is that of triage and initial stabilisation. This is an area where there is an overlap between rescue and relief efforts. Rescue is what is undertaken to release trapped or buried victims; emergency and critical care to trapped victims is still rescue. On the other hand, relief includes the medical services supplied to the majority of the population who are not trapped, as well as taking over the responsibility of medical care from the rescue team. Again, it requires rapid deployment of the most skilled persons for the job at hand, which can occur simultaneously with the SAR phase to set up medical systems to deliver patient care. The same four parameters listed above are critical to ensure appropriate and timely deployment of resources for this phase.

\section{Definitive care}

The third functional contingency (definitive care) entails the rendering of emergency as well as routine medical care to the affected population; it is usually done from temporary structures such as tented field hospitals. This category includes both relief and rehabilitation efforts, and can be divided into 3 phases: (i) early emergency care ( 24 - 48 hours after the incident); (ii) intermediate phase (48 hours - 14 days); and (iii) a late phase that may continue for many months or even years.

It should be apparent that mapping the way forward must have, at its core, clear understanding as to how to incorporate the four critical components for a medical response, as previously stated.

\section{The way forward - South Africa's medical response}

The Haiti response indicated the need for a single, official, centrally co-ordinated and properly prepared team to respond to disasters. This would be best done in conjunction with government bodies, while using the skills and experience of local NGOs. 
The specialty of emergency medicine, albeit a relative newcomer to the South African health care environment, has indeed made great strides in recent years. ${ }^{8}$ Disaster medicine is a discipline of emergency medicine that serves the dual purpose of providing medical care to the victims of a disaster as well as preparing for and mitigating such an eventuality. As such, this discipline should be a lead agency in formulating as well as facilitating a South African medical response.

A joint initiative has been proposed between the largest emergency medicine divisions in the country (at the universities of the Witwatersrand, Stellenbosch and Cape Town) to lead the way forward medically. Under this structure, an all-inclusive, multi-disciplinary medical team should be established to be trained, equipped and prepared to respond to local and international disasters. This structure would have academic credibility, be non-partisan, and include all key groups (including NGOs, government, doctors and EMS personnel). We propose that this falls under the auspices of the Emergency Medicine Society of South Africa (EMSSA), an organisation with a large member base from all aspects of emergency care (including doctors, nurses and EMS).

An international urban search and rescue course for medical personnel is currently being developed by the Medical Working Group of INSARAG. ${ }^{9}$ Attending the course should be a pre-requisite for deployment to a disaster area. A volunteer database will need to be established, consisting of personal details, skills, medical background, etc., which would further shorten the response time.

The commitment of government, private and military health services, as well as NGOs and academic structures is required to achieve these objectives. Furthermore, local acceptance of a central co-ordinating agency, rather than local individual teams preparing and deploying in isolation (which, while definitely contributing to the overall response, tends to be done in a haphazard manner and results in inefficient usage of deployable resources), is necessary. Only then will South Africa be able to respond in a unified manner.
Our final argument is that we represent a developing country. While we are relatively well off, we do not have the resources to respond half way across the world - and indeed our contribution in such settings is often minuscule by comparison with that of Western countries. Our primary responsibility is to the citizens of South Africa; we also have an obligation to the Southern African Development Community region and then to the rest of the African continent. Travelling for up to 5 days halfway around the globe to provide 3 days of assistance does not do justice to the commitment of resources and the dedication of the people involved.

\section{Conclusion}

Disasters are by their nature sudden and unpredictable; they can bring out the very best in people, with dedicated teams dropping their work and personal commitments to help in desperate and unpleasant situations. We should maximise the gain from such response by providing it in a co-ordinated and prepared manner, and focusing on where the greatest impact is possible. We are now progressing with the development of a central system, and ask readers to assist us in doing so.

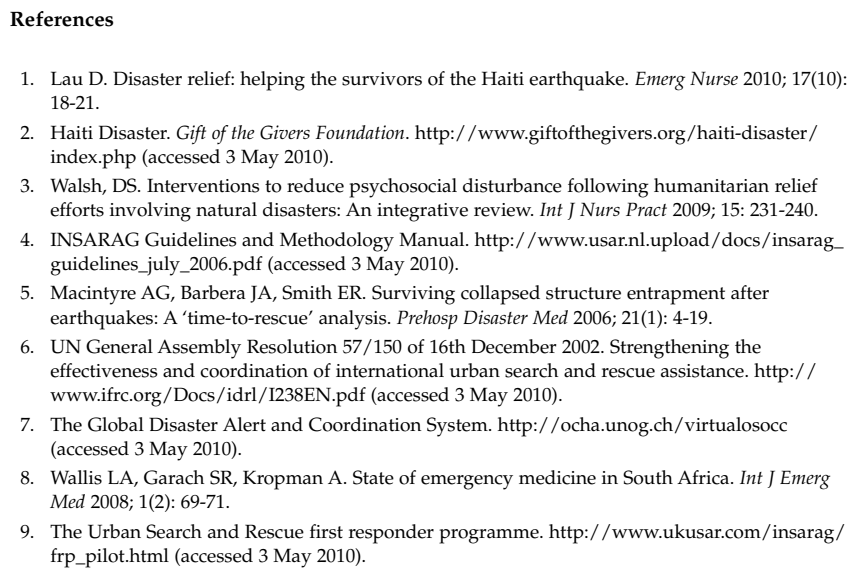

1. Lau D. Disaster relief: helping the survivors of the Haiti earthquake. Emerg Nurse 2010; 17(10): 18-21.

2. Haiti Disaster. Gift of the Givers Foundation. http://www.giftofthegivers.org/haiti-disaster/ index.php (accessed 3 May 2010).

3. Walsh, DS. Interventions to reduce psychosocial disturbance following humanitarian relief efforts involving natural disasters: An integrative review. Int J Nurs Pract 2009; 15: 231-240.

4. INSARAG Guidelines and Methodology Manual. http://www.usar.nl.upload/docs/insarag guidelines_july_2006.pdf (accessed 3 May 2010).

5. Macintyre AG, Barbera JA, Smith ER. Surviving collapsed structure entrapment after earthquakes: A 'time-to-rescue' analysis. Prehosp Disaster Med 2006; 21(1): 4-19.

6. UN General Assembly Resolution $57 / 150$ of 16 th December 2002. Strengthening the effectiveness and coordination of international urban search and rescue assistance. http:// www.ifrc.org/Docs/idrl/I238EN.pdf (accessed 3 May 2010).

7. The Global Disaster Alert and Coordination System. http://ocha.unog.ch/virtualosocc (accessed 3 May 2010).

8. Wallis LA, Garach SR, Kropman A. State of emergency medicine in South Africa. Int J Emerg Med 2008; 1(2): 69-71.

9. The Urban Search and Rescue first responder programme. http://www.ukusar.com/insarag/ frp_pilot.html (accessed 3 May 2010).

Accepted 31 May 2010. 